Volume 8. No. 1.2, 2020

International Journal of Emerging Trends in Engineering Research

Available Online at http://www.warse.org/IJETER/static/pdf/file/ijeter3881.22020.pdf

https://doi.org/10.30534/ijeter/2020/3881.22020

\title{
An Improved Adaptive Filter by IT2FLS as Tumor MRI Detector
}

\author{
Sami Hasan ${ }^{1}$, Shereen S.Jumaa ${ }^{2}$ \\ ${ }^{1,2}$ College of Information Engineering, Al-Nahrain University, Baghdad, Iraq \\ hhksami@yahoo.com \\ shireen.sadiq81@gmail.com
}

\begin{abstract}
Brain tumor edge identification framework has been of incredible guide to the human doctors. This paper presents an examination investigation of two of the best edge discovery techniques. The two strategies are the Interval Type-2 Fuzzy Logic System (IT2FLS) and the versatile channel. The examination is led utilizing MATLAB. These edge locators are tried on pictures included with 0.001 white Gaussian commotion and salt and pepper clamor. The planned calculation is an improved versatile channel with IT2FLS. This produces more clear and more splendid edges when contrasted with regular techniques results found in the writing.
\end{abstract}

Key words : Adaptive Filter, Edge Detection, Interval Type 2 Fuzzy, MRI

\section{INTRODUCTION}

Edges depict the limits between areas in a frame that underpins with segmentation and reconstruction that leads to real-time applications [1]. Edge identification is a basic stride of low-level frame handling and great edges are required for more elevated amount of processing [2]. Consequently, the tumor within a raw MRI slice may be effectively located using a high-level edge filtering [3] using Interval Type 2 Fuzzy Inference System that has been compared with Adaptive wiener Filter.

The contributions of this paper may be summarized in the following short list:

- Proposed a raw tumor MRI detection

- The Interval type 2 fuzzy logic edge detection technique is adapted.

- Adaptive wiener filter method is developed and compared with IT2FS.

\section{RELATED EXISTED WORK:}

There are no shortage of research works that presents projects to aid the physicians. The researcher in [4] made a software with edge detections method, so the brain and brain tumor may be detected as the first step for brain tumor grading research. Another paper [5] proposed an edge detection method based on the morphological gradient technique and generalized type-2 fuzzy logic. The merit of Pratt measure utilized to illustrate the advantages of using generalized type-2 fuzzy logic.

The project in [6] presented the evaluation of the conventional and commonly used edge detection techniques, that is, first and second order derivatives popularly known in image processing as gradient-based and Laplacian-based respectively. Finally, the research work [7] presented an effective edge detection method using type 2 fuzzy inference systems. These methods are battered up with morphological gradient to enhance their edge detection capabilities.

\section{PROPOSED ALGORITHM:}

The proposed algorithm has the following steps: Preprocessing:

- Converting colored image to a gray scale image

- Resize image and normalize

- Applied adaptive filter

- Edge Detection based on IT2FLS:

Fuzzification is done by triangle membership functions. The satisfactory performance are shown in Table 1.

Fuzzy Inference Rules to test each pixel using the fuzzy rule-phase. The Fuzzy Inference System (FIS) tested consists of four inputs and one output. A $3 \times 3$ window mask is used for scanning purpose as shown in Figure 1

\begin{tabular}{|l|l|l|}
\hline $\mathrm{Z}_{1}$ & $\mathrm{Z}_{2}$ & $\mathrm{Z}_{3}$ \\
\hline $\mathrm{Z}_{4}$ & $\mathrm{Z}_{5}$ & $\mathrm{Z}_{6}$ \\
\hline $\mathrm{Z}_{7}$ & $\mathrm{Z}_{8}$ & $\mathrm{Z}_{9}$ \\
\hline
\end{tabular}

Figure 1: The coefficients of $3 \times 3$ matrix (2).

The total number of rules that generate Edge is four, the two are considered Non-Edge. The fuzzy logic rules-based system rules are displayed as in Table 2. 
Sami Hasan et al., International Journal of Emerging Trends in Engineering Research, 8(1.2), 2020, 277- 282

Table 1: Fuzzy membership function for input and output

\begin{tabular}{|c|c|c|c|c|}
\hline \multicolumn{5}{|c|}{ Fuzzy Input } \\
\hline Name & & Range & & MF Type \\
\hline D1 (Low Upper) & {$[-0.05293$} & 30.0052 & $0.0634]$ & Triangular \\
\hline D1 (Low Lower) & {$[-0.0451$} & 0.00152 & $0.0482]$ & Triangular \\
\hline D1 (Middle Upper) & {$[0.1511$} & 0.1928 & $0.2345]$ & Triangular \\
\hline $\begin{array}{l}\text { D1 (Middle } \\
\text { Lower) }\end{array}$ & {$[0.1292$} & 0.1936 & $0.258]$ & Triangular \\
\hline D1 (High Upper) & {$[0.3539$} & 0.4028 & $0.4517]$ & Triangular \\
\hline D1 (High Lower) & {$[0.3354$} & 0.4 & $0.4646]$ & Triangular \\
\hline D2 (Low Upper) & {$[-0.067$} & 0.0031 & $0.0740]$ & Triangular \\
\hline D2 (Low Lower) & {$[-0.055-0$} & 0.00059 & $0.0545]$ & Triangular \\
\hline D2 (Middle Upper) & {$[0.1448$} & 0.1928 & $0.2408]$ & Triangular \\
\hline $\begin{array}{l}\text { D2 (Middle } \\
\text { Lower) }\end{array}$ & {$[0.1219$} & 0.1924 & $0.2629]$ & Triangular \\
\hline D2 (High Upper) & {$[0.3503$} & 0.4 & 0.4497] & Triangular \\
\hline D2 (High Lower) & {$[0.3241$} & 0.3988 & $0.4735]$ & Triangular \\
\hline D3 (Low Upper) & {$\left[\begin{array}{lll}-0.046 & 0\end{array}\right.$} & 0.00396 & $0.05398]$ & Triangular \\
\hline D3 (Low Lower) & {$[-0.0401$} & 0.00114 & $0.0424]$ & Triangular \\
\hline D3 (Middle Upper) & {$[0.0952$} & 0.1452 & $0.1951]$ & Triangular \\
\hline $\begin{array}{l}\text { D3 (Middle } \\
\text { Lower) }\end{array}$ & {$[0.1102$} & 0.1446 & $0.179]$ & Triangular \\
\hline D3 (High Upper) & {$[0.25$} & 0.3 & $0.35]$ & Triangular \\
\hline D3 (High Lower) & {$[0.2639$} & 0.3006 & $0.3373]$ & Triangular \\
\hline D4 (Low Upper) & {$[-0.0459$} & 0.0039 & 0.0539] & Triangular \\
\hline D4 (Low Lower) & {$[-0.0401$} & 0.00114 & $0.0424]$ & Triangular \\
\hline D4 (Middle Upper) & {$[0.09696$} & 0.145 & $0.193]$ & Triangular \\
\hline $\begin{array}{l}\text { D4 (Middle } \\
\text { Lower) }\end{array}$ & {$[0.1104$} & 0.1445 & $0.1786]$ & Triangular \\
\hline D4 (High Upper) & {$[0.2639$} & 0.3006 & $0.3373]$ & Triangular \\
\hline D4 (High Lower) & {$[0.25$} & 0.3 & $0.35]$ & Triangular \\
\hline
\end{tabular}

Table 2: Fuzzy rules

\begin{tabular}{|c|c|c|c|c|}
\hline \multicolumn{4}{|c|}{ Fuzzy Inputs } & \multirow{2}{*}{$\begin{array}{c}\text { Fuzzy } \\
\text { Outputs } \\
\text { S output }\end{array}$} \\
\hline D1 & D2 & D3 & D4 & \\
\hline $\begin{array}{l}\text { High } \\
\text { Upper }\end{array}$ & $\begin{array}{l}\text { High } \\
\text { Upper }\end{array}$ & $\begin{array}{l}\text { High } \\
\text { Upper }\end{array}$ & $\begin{array}{l}\text { High } \\
\text { Upper }\end{array}$ & Edge \\
\hline $\begin{array}{l}\text { High } \\
\text { Lower }\end{array}$ & $\begin{array}{l}\text { High } \\
\text { Lower }\end{array}$ & $\begin{array}{l}\text { High } \\
\text { Lower }\end{array}$ & $\begin{array}{l}\text { High } \\
\text { Lower }\end{array}$ & Edge \\
\hline $\begin{array}{r}\text { Middle } \\
\text { Upper }\end{array}$ & $\begin{array}{l}\text { Middle } \\
\text { Upper }\end{array}$ & $\begin{array}{l}\text { Middle } \\
\text { Upper }\end{array}$ & $\begin{array}{l}\text { Middle } \\
\text { Upper }\end{array}$ & Edge \\
\hline $\begin{array}{l}\text { Middle } \\
\text { Lower }\end{array}$ & $\begin{array}{l}\text { Middle } \\
\text { Lower }\end{array}$ & $\begin{array}{l}\text { Middle } \\
\text { Lower }\end{array}$ & $\begin{array}{l}\text { Middle } \\
\text { Lower }\end{array}$ & Edge \\
\hline $\begin{array}{l}\text { Low } \\
\text { Upper }\end{array}$ & $\begin{array}{l}\text { Low } \\
\text { Upper }\end{array}$ & $\begin{array}{l}\text { Low } \\
\text { Upper }\end{array}$ & $\begin{array}{l}\text { Low } \\
\text { Upper }\end{array}$ & No Edge \\
\hline $\begin{array}{l}\text { Low } \\
\text { Lower }\end{array}$ & $\begin{array}{l}\text { Low } \\
\text { Lower }\end{array}$ & $\begin{array}{l}\text { Low } \\
\text { Lower }\end{array}$ & $\begin{array}{c}\text { Low } \\
\text { Lower }\end{array}$ & No Edge \\
\hline
\end{tabular}

\section{EXPERIMENT RESULTS}

The proposed Fuzzy logic edge detection approach is designed and tested for both noisy and noise free images. The main goal of this paper is to compare proposed method (Interval type -2 fuzzy logic) with using adaptive filter for noise removable and its effect on edge detection to various images contents. The test images have variety of contents (curves, angles, smooth line and hard line) for testing the proposed work. In the first phase (preprocessing), the input image is converted to gray scale which take less time of processing than color format, in addition, a rescale has done on gray scale image to fix size (200x200) and normalize. The original noise free image samples and those samples after adding Gaussian and Salt and Pepper noise are depicted in Fig.2. The performances of proposed IT2FIS method and IT2FIS with adaptive filter for noise removable are compared and tested first for noise free images. Then two types of noise are added to image samples and the edge detection performances are evaluated using Mean Square Error (MSE) and Peak Signal to Noise Ratio (PSNR) and number of edges that are detected. Fig.3 and Fig.4 show the edge detection results for free of noise images with and without adaptive filter respectively. It is clear that fuzzy technique produces clear and bright edges but with using adaptive filter, the fuzzy technique produces clearer and brighter edges as compared without using adaptive filter results. The performance of the previous edge detection process is evaluated using MSE, PSNR and sum of edges detected. The results are depicted in Table 3 contents the MSE and PSNR results, and Table 4 contents sum of edge detected using IT2FLS and IT2FLS with adaptive filter. The results show method IT2FLS gives the highest number of edges detected than IT2FLS with adaptive filter. 


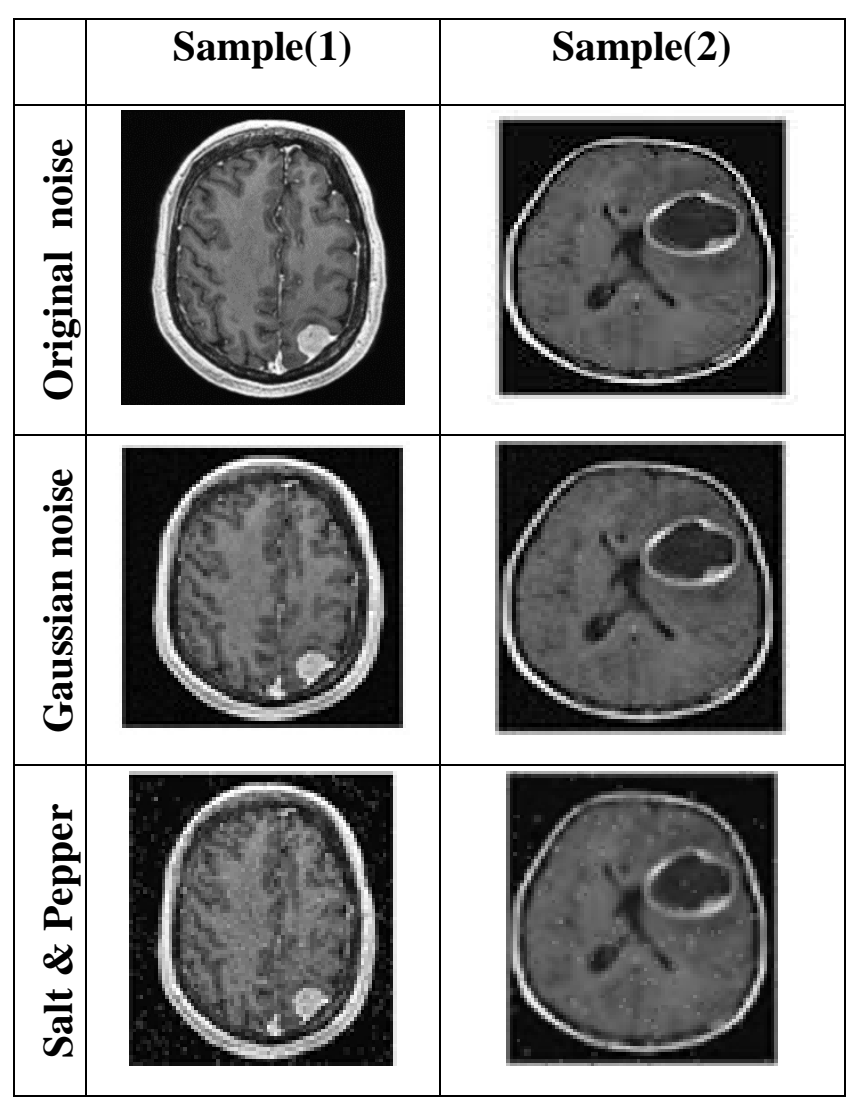

Figure 2: The original noisy and noise free image samples

Table 3: MSE and PSNR for edge detection in noise free images.

\begin{tabular}{|c|c|c|}
\hline Measurement & Sample1 & Sample2 \\
\hline MSE & 0.0746 & 0.0061 \\
\hline PSNR & 59.4011 & 70.3012 \\
\hline \multicolumn{2}{|c|}{ IT2FLS } & $\begin{array}{l}\text { IT2FLS(final } \\
\text { processing) }\end{array}$ \\
\hline
\end{tabular}

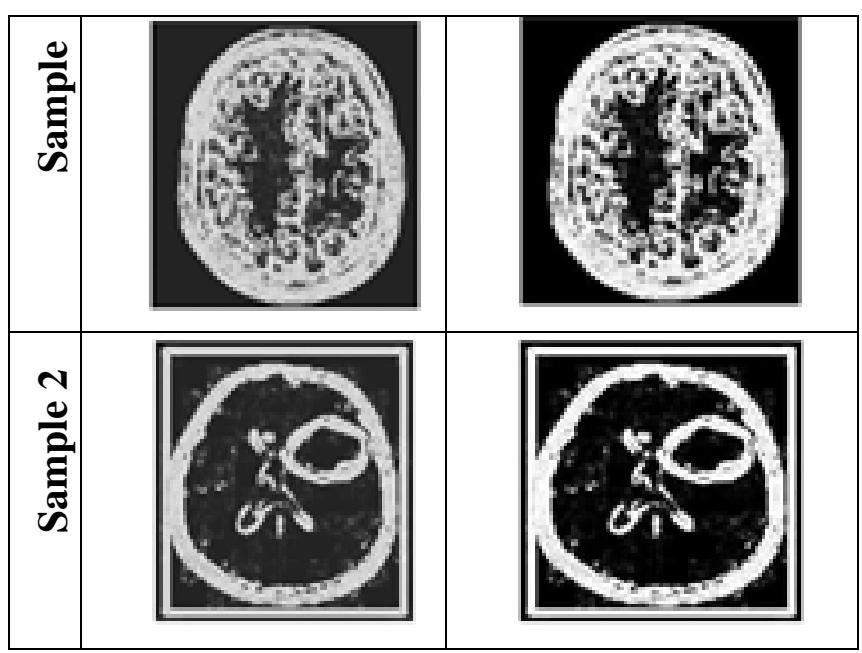

Figure 3: Edge detection results for noise free image using IT2FLS.

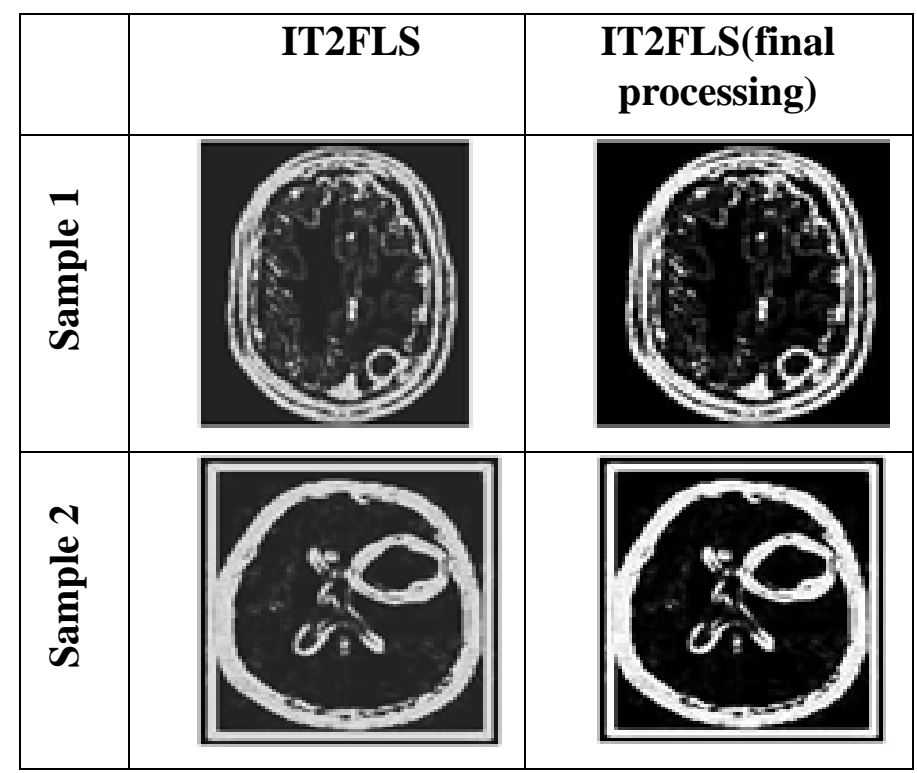

Figure 4: Edge detection results for noise free image using IT2FLS and adaptive filter.

Table 4: Sum of detected in noise free images using IT2FLS.

\begin{tabular}{|c|c|c|}
\hline $\begin{array}{c}\text { IT2FLS\&Adaptive } \\
\text { Filter }\end{array}$ & Sample1 & Sample2 \\
\hline MSE & 0.0394 & 0.0072 \\
\hline PSNR & 62.1739 & 69.5655 \\
\hline
\end{tabular}

\section{Edge Detection of Images Corrupted With Gaussian Noise}

Gaussian noise of zero mean and 0.001 variance has been applied to the same image samples, in edge detection phase, a comparison between IT2FLS and IT2FLS with adaptive filter approach is depicted in Fig.5. From this Figure, the IT2FLS for edge detection may not remove Gaussian noise, however using IT2FLS with adaptive filter for edge detection process produces clearer edges as compared to first one. Finally, an informatics metric has been calculated to find the performance of IT2FLS and proposed IT2FLS with adaptive filter. The comparison has been used on both noisy and free noise samples of images and between IT2FLS for edge detection and IT2FLS with adaptive filter methods. The performance of the previous edge detection process is evaluated using MSE, PSNR and sum of edges detected compared for IT2FLS method and IT2FLS with adaptive filter method. The results are depicted in Table 5 contents the MSE and PSNR for IT2FLS edge detector between noise free images and images corrupted with Gaussian noise. Table 6 contents the MSE and PSNR results for IT2FLS edge detector with adaptive filter between noise free images and images corrupted with Gaussian noise. Table 7 contents the sum of edge detected for IT2FLS edge detector and IT2FLS edge detector with adaptive filter for noise free images and images corrupted with Gaussian noise .The results show that IT2FLS edge detector with adaptive filter method gives the lowest MSE and highest PSNR compared with first one. However 
that IT2FLS edge detector with adaptive filter method fuzzy edge detection technique produces the brighter visual appearance as shown in Fig.5,because it can noise removed therefore the sum of edges that detected with it less than IT2FLS without adaptive filter because it deal with noise as edges .

Table 5: MSE and PSNR for IT2FLS edge detection when adding Gaussian noise.

\begin{tabular}{|c|c|c|}
\hline IT2FLS & Sample1 & Sample2 \\
\hline MSE & 0.0796 & 0.0929 \\
\hline PSNR & 59.1202 & 58.4520 \\
\hline
\end{tabular}

Table 6: MSE and PSNR for IT2FLS adaptive filter edge detection when adding Gaussian noise.

\begin{tabular}{|c|c|c|}
\hline Methods & Sample1 & Sample2 \\
\hline IT2FLS & 16698 & 26189 \\
\hline $\begin{array}{c}\text { IT2FLS } \\
\text { \&Adaptive Filter }\end{array}$ & 8116 & 13412 \\
\hline
\end{tabular}

Table 7: Sum of edge detection in Gaussian noisy images

\begin{tabular}{|c|c|c|}
\hline Methods & Sample1 & Sample2 \\
\hline Original & 16698 & 13412 \\
\hline IT2FLS & 25173 & 23796 \\
\hline $\begin{array}{c}\text { IT2FLS } \\
\text { \&Adaptive Filter }\end{array}$ & 12003 & 12893 \\
\hline
\end{tabular}

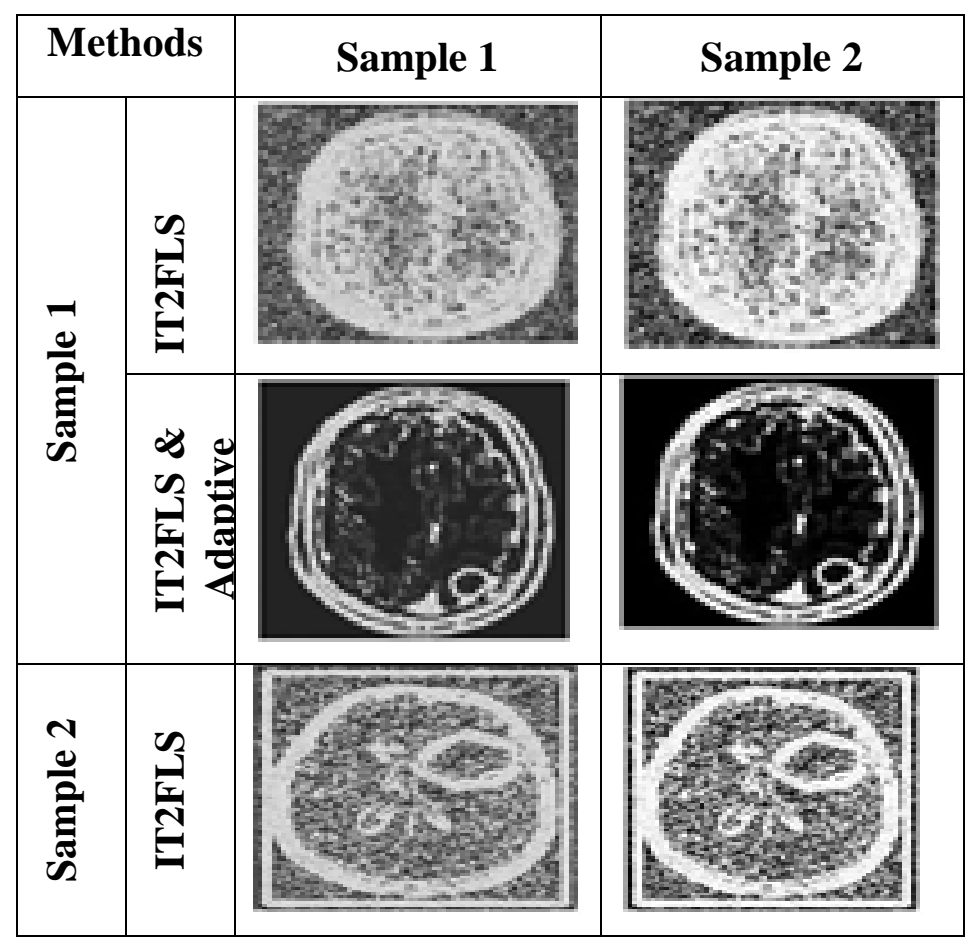

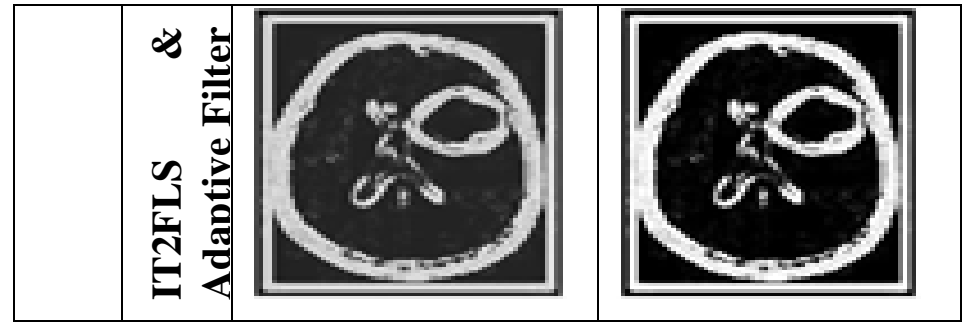

Figure 5:.Edge detection of images corrupted with Gaussian noise of zero mean and 0.001 variance.

\section{Edge Detection of Images with Salt And Pepper Noise}

The previous tests are repeated with a different type of noise which is called salt and pepper. The results of edge detection of images corrupted with salt and pepper noise of density 0.045 (which means that $04.5 \%$ of the image is corrupted) are shown in Fig.6. From these results, the IT2FLS edge detection with adaptive filter results techniques is superior to the IT2FLS edge detector without adaptive filter that is sensitive to noise. The IT2FLS technique produces good edge detection without using filter but it produces the better edge when coupled with adaptive filter to noise removable before edge detection process.

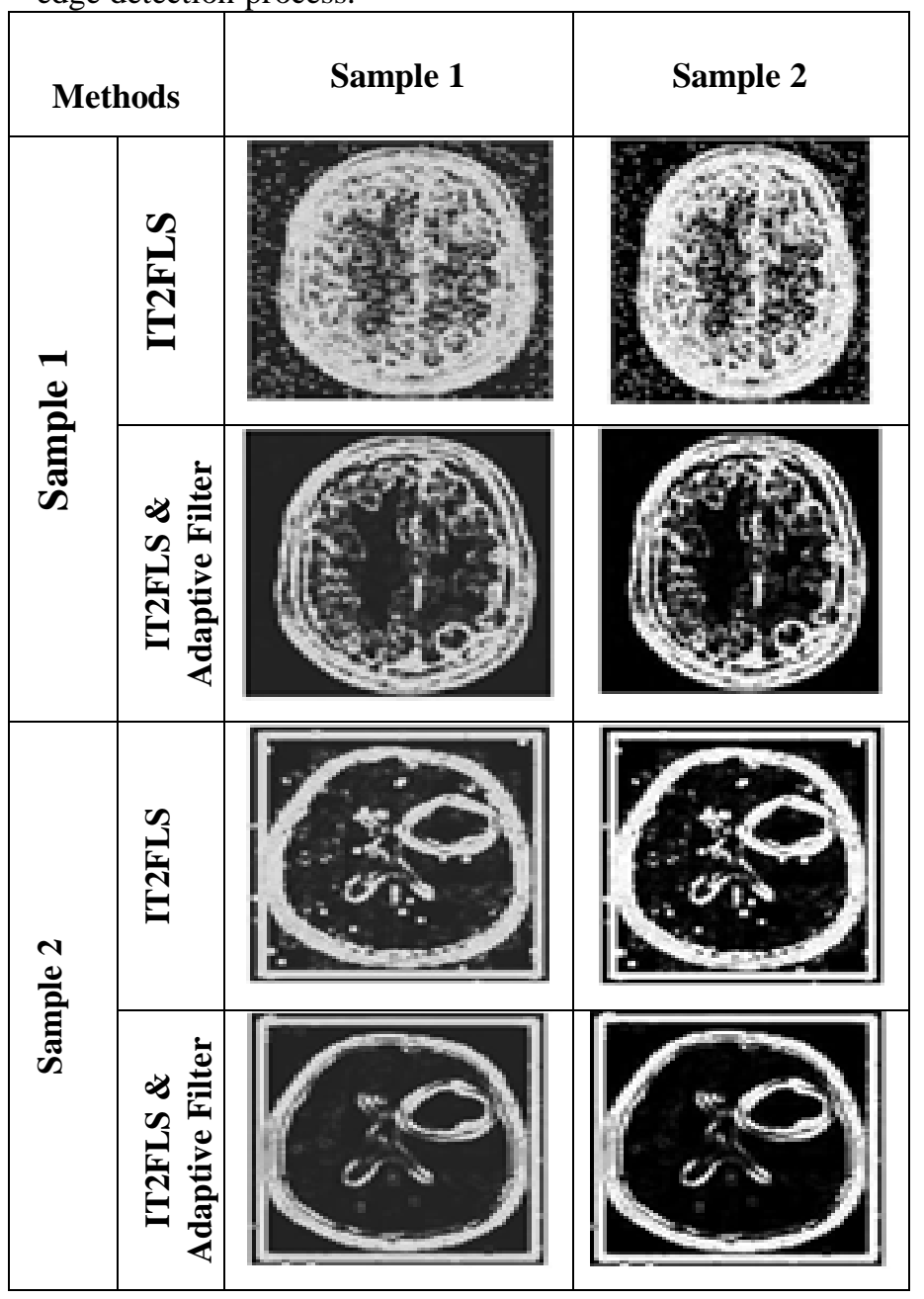

Figure 6: Edge detection of images corrupted with salt and pepper noise with density 0.045 . 
Sami Hasan et al., International Journal of Emerging Trends in Engineering Research, 8(1.2), 2020, 277- 282

Informatics metric MSE and PSNR for both methods for sample images are discussed in Tables 8 and 9 ,where Salt and Pepper noise filter applied with density 0.045 . Then the performances of the previous methods were tested by increasing the added salt and pepper noise density to 0.45 which means that $45 \%$ image is corrupted. The evaluation in table 10 shows that IT2FLS with adaptive filter method produces the lowest MSE and highest PSNR respect to that one.

Table 8.MSE and PSNR for IT2FLS edge detection when adding salt and pepper noise.

\begin{tabular}{|c|c|c|}
\hline IT2FLS & Sample1 & Sample2 \\
\hline MSE & 0.0131 & 0.0265 \\
\hline PSNR & 66.9538 & 63.9007 \\
\hline
\end{tabular}

Table 9. MSE and PSNR for IT2FLS \&adaptive filter edge detection when adding salt and pepper noise

\begin{tabular}{|c|c|c|}
\hline IT2FLS & Sample1 & Sample2 \\
\hline MSE & 0.0022 & 0.0062 \\
\hline PSNR & 74.7900 & 70.2389 \\
\hline
\end{tabular}

Table 10. Sum of edges detection in salt and pepper noisy images

\begin{tabular}{|c|c|c|}
\hline Methods & Sample1 & Sample2 \\
\hline Original & 16698 & 13412 \\
\hline IT2FLS & 17463 & 14011 \\
\hline $\begin{array}{c}\text { IT2FLS } \\
\text { \&Adaptive } \\
\text { Filter }\end{array}$ & 11147 & 11791 \\
\hline
\end{tabular}

\section{CONCLUSION:}

Interval type 2 fuzzy logic with adaptive wiener filter method produces bright and clear edge detection results for MRI images that corrupted with noises (Salt and pepper noise ,Gaussian), while IT2FLS without using adaptive filter method may not give such good results because consider noise pixels as edges found in the image. Comparatively, the above results leads to the conclusion that fuzzy logic method can utilize the benefits of the adaptive wiener filter to give smooth and bright edges as shown clearly while IT2FLS without filter method could not detect the edges in such a good way. In general, IT2FLS and adaptive filter technique proves to be an effective edge detection method with a superior performance to that of the compared classical edge detection and fuzzy logic type 1 methods.
The future work will be extended the presented 2D edge filtering model to be developed for a 3D grayscale edge filtering model [8]. Consequently, this work may be realized in a reconfigurable hardware such as FPGA [9-14] for real-time character recognition applications $[15$.

\section{REFERENCES:}

1. Hasan S, Amer A. Applying fuzzy artificial neural network OSPF to develop smart routing protocol algorithm. Journal of Fundamental and Applied Sciences. 2018;10(4S):659-62.

2. Thakur P, Azam A. Edge detection through integrated morphological gradient and fuzzy logic approach. IJSETR. 2015;4(5):1613-6.

3. Hasan S, Jumaa SS. Raw tumor MRI edge detection using interval Type 2 Fuzzy inference system and adaptive filter. Journal of Fundamental and Applied Sciences. 2018;10(5S).

4. Rulaningtyas R, Ain K. Edge detection for brain tumor pattern recognition. Instrumentation, Communications. InInformation Technology, and Biomedical Engineering (ICICI-BME), 2009 International Conference on 2009 Nov (pp. 23-25).

5. Fataniya B, Kar M, Joshi G, Zaveri DT, Acharya DS. Edge Detection of Microscopic Image. International Journal of Electronics and Communication Engineering \& Technology (IJECET). 2016 May;7(3):1-0.

6. Bature UI, Murtala AB, Nasir AY. Evaluation Of Image Detection Techniques. Journal of Multidisciplinary Engineering Science and Technology (JMEST). 2015 Dec;2(12).

7. Leordeanu M, Sukthankar R, Sminchisescu C. Generalized boundaries from multiple image interpretations. IEEE transactions on pattern analysis and machine intelligence. 2014 Jul;36(7):1312-24.

8. Hasan S, Boussakta S, Yakovlev A. Improved parameterized efficient FPGA implementations Improved of parallel 1-D filtering algorithms using Xilinx System Generator. InThe 10th IEEE International Symposium on Signal Processing and Information Technology 2010 Dec 15 (pp. 382-387). IEEE.

9. Hasan S, Boussakta S, Yakovlev A. Parameterized FPGA-based architecture for parallel 1-D filtering algorithms. InInternational Workshop on Systems, Signal Processing and their Applications, WOSSPA 2011 May 9 (pp. 171-174). IEEE.

10. Hasan S. Performance-vetted 3-D MAC processors for parallel volumetric convolution algorithm: A 256x 256× 20 MRI filtering case study. In2016 Al-Sadeq International Conference on Multidisciplinary in IT and Communication Science and Applications (AIC-MITCSA) 2016 May 9 (pp. 1-6). IEEE.

11. Humaidi AJ, Hassan $\mathrm{S}$ and Fadhel MA. Rapidly-fabricated nightly-detected lane system: An 
Sami Hasan et al., International Journal of Emerging Trends in Engineering Research, 8(1.2), 2020, 277- 282

FPGA implemented architecture. The Asian International Journal of Life Sciences. 2018; 16(1): 343-355.

12. Humaidi AJ, Hassan S and Fadhel MA. FPGA-based lane-detection architecture for autonomous vehicles: A real-time design and development. The Asian International Journal of Life Sciences.2018; 16(1): 223-237.

13. Humaidi AJ, Hasan S, Al-Jodah AA. Design of Second Order Sliding Mode for Glucose Regulation Systems with Disturbance. International Journal of Engineering \& Technology. 2018;7(2.28):243-7.

14. Ar-Ramahi SK. A Fuzzy Recognition Model for Arabic Handwritten Alphabet. Journal of Engineering .900-2891:(3)14;2008

15. Hasan S, Amer A. Real-time vehicle ID identification using parallel-joining wireless sensor network. Journal of Fundamental and Applied Sciences. 2018;10(4S):663-6. 